\title{
Preparation and characterization of ceramic foam supported nanocrystalline zeolite catalysts
}

\author{
Florina-Corina Buciuman*, Bettina Kraushaar-Czarnetzki \\ Institute of Chemical Process Engineering (CVT), University of Karlsruhe, D-76128 Karlsruhe, Germany
}

\begin{abstract}
The influence of the viscosity of the ceramic slip on the manufacture of ceramic foams by the polymer sponge method was studied. The foams were coated with silicalite $(100 \mathrm{~nm})$ and HZSM-5 $(650 \mathrm{~nm})$ crystals by dipping them in a zeolite suspension without binder additives. The amount of zeolite loaded can be controlled through the zeolite content of the dipping suspension. Uniform coatings are achieved starting with about $1 \mathrm{~g}$ zeolite $/ \mathrm{m}^{2}$ foam. () 2001 Elsevier Science B.V. All rights reserved.
\end{abstract}

Keywords: Ceramic foam; Catalyst; Zeolite; Silicalite

\section{Introduction}

Structured catalysts consisting of catalytically active materials supported on open-cell ceramic foam monoliths have been successfully tested in the last decade [1-3]. The possibility to operate at high space velocity with low pressure drop and the shaping of the catalytically active material as a thin layer having low diffusional resistance allow substantial improvements of selectivity in processes where the target product is the intermediate of a successive reaction pathway. Other envisaged applications of foam carriers refer to the processing of high throughput gas streams (end-of-pipe exhaust control, burners). In comparison to honeycomb monoliths, foam structures offer in addition to the low pressure drop the advantage of a turbulent flow enhancing the mass and heat transfer between the fluid phase and the catalyst washcoat, and they also allow radial mixing.

\footnotetext{
* Corresponding author.

E-mail address: florina.buciuman@ciw.uni-karlsruhe.de (F.-C. Buciuman).
}

The deposition of active catalyst phases on the surface of a monolith proceeds conventionally by coating the monolith with a slurry of catalytic material, which contains also a binding material to ensure the adhesion of the layer [4]. Another possibility is to pre-coat the monolith with a high-surface washcoat and to bring subsequently the active material onto this carrier [5].

The coating of ceramic monoliths with zeolite crystals can proceed either by starting from synthesized zeolite powder, or by the direct synthesis of zeolite in the form of a layer on the monolith surface. The first method usually involves the addition of a binder material to the zeolite slurry in order to yield an adherent coating [6]. However the binder, which has mostly smaller crystals than the zeolite, may complicate the diffusion of gases inside the washcoat, or can block the entrance in the zeolite micropores by surrounding the zeolite crystals. The synthesis of zeolite crystals directly on ceramic surfaces was performed by prolonged contacting of the ceramic body with a zeolite synthesis mixture under hydrothermal conditions [7-10] and yielded densely packed, well bonded coatings of large zeolite crystals. Although no data are given concerning the permeability of these layers for 
intercrystalline (mesopore) diffusion, the examination of the published micrographs $[9,10]$ suggests that this process could be hindered because of the very dense packing and intergrowth of the zeolite crystals.

The aim of the present work is to study the possibility to manufacture zeolite coated ceramic foams without the addition of binder materials, by employing zeolite powders synthesized previously in the absence of the ceramic carrier. The catalysts are designed to be used in the methanol-to-olefin conversion, where previous studies have shown that the yields of lower olefins are enhanced by processing methanol at high flow rates [11] and by the use of small zeolite crystals as catalysts [12]. By using this preparation procedure, the morphology of the zeolite layer should correspond to a random packing of crystals thus allowing intercrystalline diffusion.

\section{Experimental}

The ceramic foam carriers were made by using the polymer foam replication method [13]. Polymer sponges of different pore sizes in the range of 10-80 ppi (pores per inch) were coated with aqueous slips containing ceramic precursors and appropriate additives, to yield the desired ceramic compositions. The viscosity of the slips was varied by water addition starting with the most viscous slurry. The viscosity measurements were performed on a Haake RS150 rheometer in a cone-plate configuration at a constant shear stress of $20 \mathrm{~Pa}$.

The coated polymer sponges were passed through rollers preset at $80 \%$ compression to expel the excessive slurry, then dried at room temperatures and heated up to the sintering temperature of the ceramic material. The phase composition of the resulted ceramic bodies was analyzed with a Siemens D-500 diffractometer, after a previous ball milling.

The coating of the ceramic foams was carried out by using suspensions of zeolites as follows:

1. a silicalite with the MFI structure $(\mathrm{Si} / \mathrm{Al}$ ratio $=$ $\infty$ ), as-synthesized, containing the template (TPA-OH), in the form of a stable colloidal suspension of crystals with a mean particle size of $100 \mathrm{~nm}$;

2. an HZSM-5 zeolite ( $\mathrm{Si} / \mathrm{Al}$ ratio $=39$ ), available as a powder with a mean particle size of $650 \mathrm{~nm}$, which was dispersed in deionized water by using an ultrasonic bath.

Deionized water was further added to these suspensions in an amount appropriate to achieve the desired zeolite content. The ceramic foam monoliths, cut into pieces of $5 \times 5 \times 20 \mathrm{~mm}$ were dipped into the zeolite suspension for $30 \mathrm{~min}$ at room temperature, at a weight ratio zeolite:suspension of 1:10, then the excessive material was removed from the pores by blowing it with compressed air. The pieces were dried at $343 \mathrm{~K}$, then heated at a rate of $3 \mathrm{~K} / \mathrm{min}$ to $823 \mathrm{~K}$ and maintained at $823 \mathrm{~K}$ for $3 \mathrm{~h}$.

The amounts of zeolite loaded were determined by calculating the difference between the surface area of the sample and the surface area of the unloaded ceramic carrier. The surface areas were measured after the BET method on a Micromeritics ASAP 2010 equipment, by using krypton as an adsorptive for unloaded ceramic samples and argon for those loaded with zeolite.

The surface morphology of the loaded ceramic foams was examined by scanning electron microscopy (SEM) on a Hitachi S-4500 electron microscope.

\section{Results and discussion}

\subsection{Manufacture of ceramic foams}

By using different compositions of raw materials and additives, ceramic foams were manufactured consisting of alumina-mullite, china, cordierite or steatite, having mean pore sizes in the range of 10-80 ppi.

The viscosity of the slip used to coat the polymer sponges in relation to the pore size of the sponges was found to influence the quality of the ceramic foams. The viscosity of several ceramic slips employed to manufacture alumina-mullite composites are represented in Fig. 1. When the slip was too thick for a certain pore size, it could not penetrate the sponge pieces but it coated only the outer surface with a more or less continuous layer. The ceramic monoliths thus obtained were mostly closed outside and had empty spaces inside. When the slip was too thin, it did not coat properly the struts of the sponges and the resulting bodies were too fragile after sintering and collapsed during the calcination. A certain range of 


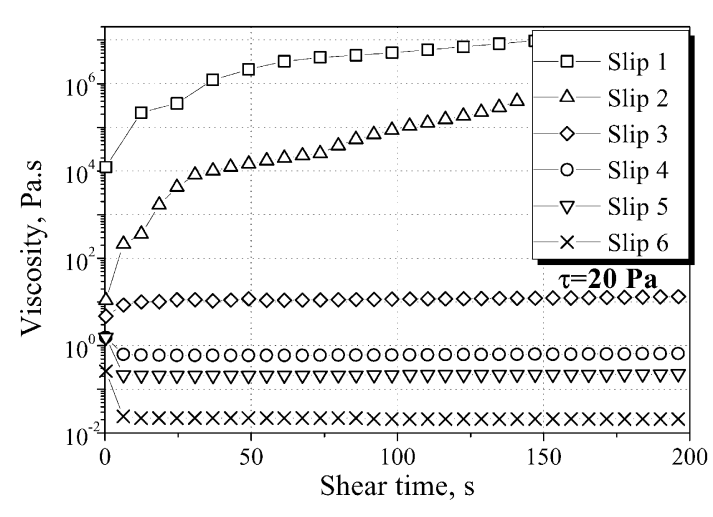

Fig. 1. The viscosity of slips used to manufacture alumina-mullite ceramic foams as a function of the shear time, measured at a shear stress of $20 \mathrm{~Pa}$.

optimal thickness of the ceramic slurry was found to ensure a good quality for the foams of a given pore size. For the alumina-mullite foams, the optimal viscosity of the slips was in the range of $10^{5}-10^{7} \mathrm{~Pa}$ (for 10-20 ppi foams), 1-10 Pas (for 30-45 ppi foams) and $0.02-0.2 \mathrm{~Pa}$ s (for 60-80 ppi foams).

The surface areas of the 45 ppi foams of different ceramic compositions, used in the further catalysts manufacture, are reported in Table 2.

\subsection{Ceramic foams coated with silicalite}

Samples of a 45 ppi alumina-mullite foam were coated with template-containing silicalite suspended in water at different concentrations, the $\mathrm{pH}$ of the suspensions being 9.3. The characteristics of the zeolite/ceramic foam bodies are displayed in Table 1. The surface area of silicalite was $406 \mathrm{~m}^{2} / \mathrm{g}$ and that of the foam was $0.023 \mathrm{~m}^{2} / \mathrm{g}$.

The data of Table 1 suggest that there is a linear dependence between the zeolite content of the dipping suspension and the resulted silicalite loading on the carrier. This suggests the possibility to control the amount of zeolite loaded by adjusting the concentration of the dipping suspension.

The coating of different foam carriers having a pore size of 45 ppi with a template-containing silicalite suspension of $1.1 \mathrm{wt} . \%$ and $\mathrm{pH}=9.3$ yielded the results shown in Table 2.

When related to the mass of the ceramic monolith, the amount of silicalite loaded on foams of different oxide composition appears as quite different, varying with a factor of almost three when going from alumina-mullite (the lowest loading) to steatite (the highest loading). A possible explanation for this behavior arise from the microscopic examination of the surface of unloaded ceramic foams, correlated with their surface area data. Steatite and cordierite foams display a very rough, irregular surface with numerous pores, whereas alumina-mullite and china show a comparatively smoother surface, similar to an orange skin. When examining the surface-specific silicalite loading of the foams (Table 2), most of them (alumina-mullite, cordierite and steatite) show about the same values. This indicates that the loading of

Table 1

Characteristics of silicalite coatings on a 45 ppi alumina-mullite foam as a function of the zeolite content of the dipping suspension

\begin{tabular}{llll}
\hline & \multicolumn{3}{l}{ Concentration of zeolite suspension (wt.\%) } \\
\cline { 2 - 4 } & 1.1 & 1.4 & 6.8 \\
\hline Surface area of the loaded zeolite, $S_{\text {zeo }}\left(\mathrm{m}^{2} / \mathrm{g}\right)$ & 3.82 & 5.29 & 25.10 \\
Zeolite loading $(\mathrm{g} / 100 \mathrm{~g}$ foam) & 0.94 & 1.30 & 6.6 \\
Zeolite loading $\left(\mathrm{g} / \mathrm{m}^{2}\right.$ foam) & 0.41 & 0.57 & 2.68 \\
\hline
\end{tabular}

Table 2

Comparison of silicalite coatings over different ceramic foam carriers of 45 ppi by using a 1.1 wt.\% zeolite suspension

\begin{tabular}{|c|c|c|c|c|}
\hline Carrier & Alumina-mullite & China & Steatite & Cordierite \\
\hline Surface area of the unloaded foam $\left(\mathrm{m}^{2} / \mathrm{g}\right)$ & 0.023 & 0.012 & 0.052 & 0.044 \\
\hline Surface area of the loaded zeolite $\left(\mathrm{m}^{2} / \mathrm{g}\right)$ & 3.82 & 5.97 & 10.46 & 7.28 \\
\hline Zeolite loading ( $\mathrm{g} / 100 \mathrm{~g}$ foam $)$ & 0.94 & 1.47 & 2.58 & 1.79 \\
\hline Zeolite loading ( $\mathrm{g} / \mathrm{m}^{2}$ foam $)$ & 0.41 & 1.22 & 0.50 & 0.41 \\
\hline
\end{tabular}




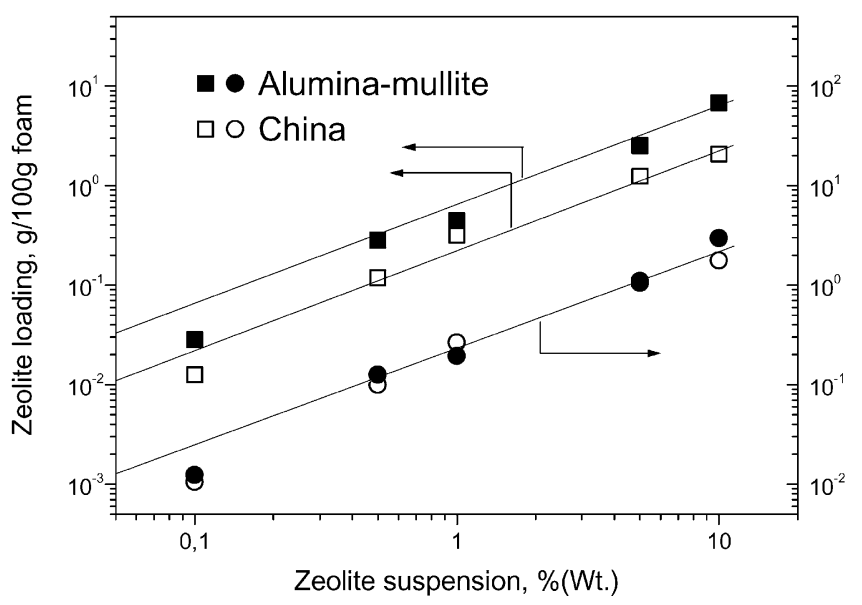

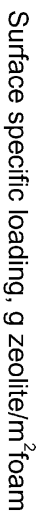

Fig. 2. HZSM-5 loading as a function of the zeolite content of the coating suspension, for alumina-mullite and china foams of 45 ppi.

a)

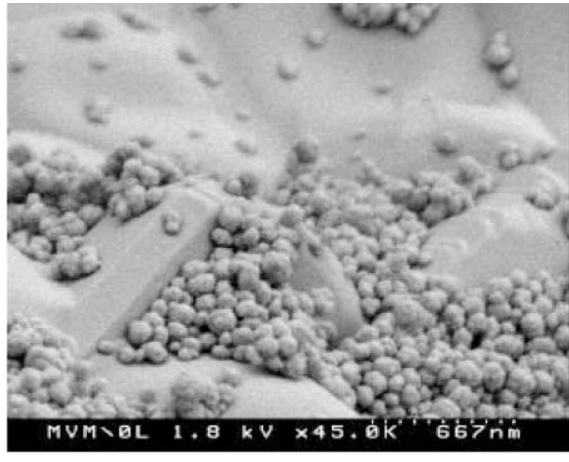

c)

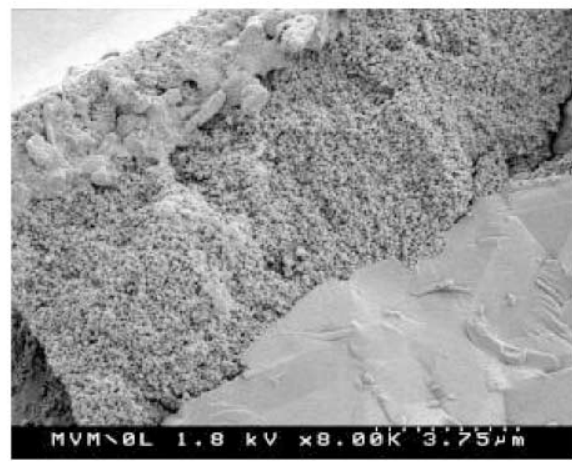

b)
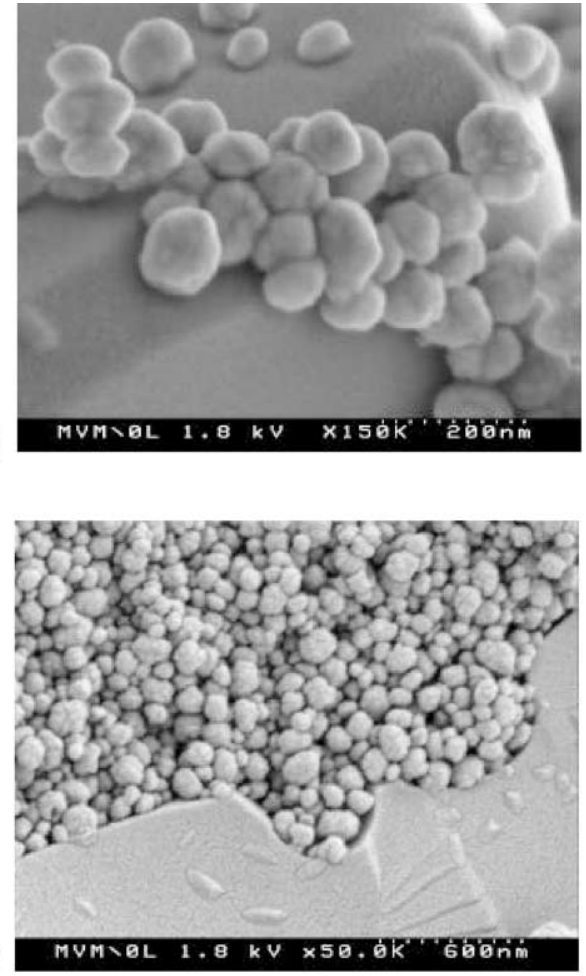

Fig. 3. SEM pictures of the foam surface coated with zeolite: (a) about $0.01 \mathrm{~g}$ zeolite $/ \mathrm{m}^{2}$ foam; (b) detail from (a); (c) about $3 \mathrm{~g}$ zeolite $/ \mathrm{m}^{2}$ foam; (d) detail from (d). 
these foams is unspecific, being influenced merely by the amount of zeolite suspension that is retained in the pores and on the surface of the material. The china foam shows on the contrary a much higher surface-specific silicalite loading, which suggests that some sort of specific adsorption or bonding of the silicalite nanocrystals takes place already during the dipping of the foam in the suspension.

\subsection{Ceramic foams coated with HZSM-5}

The coating with zeolite HZSM-5 $\left(S_{\mathrm{BET}}=\right.$ $420 \mathrm{~m}^{2} / \mathrm{g}$ ) was performed over alumina-mullite and china foams. In order to achieve zeolite loadings in a wider range, the foams were dipped in suspensions having $0.1-10 \mathrm{wt} . \%$ HZSM-5 $(\mathrm{pH}=5)$. The results are displayed in Fig. 2.

The amounts of HZSM-5 loaded on the aluminamullite foam are similar to those of silicalite and show a linear dependence on the concentration of the dipping zeolite suspension. Here, however, the china carrier has a much lower loading compared to silicalite. In fact, when related to the surface area of the foam, the ZSM-5 loading is the same irrespective of the foam material, showing a non-specific coating. The reasons for the different behavior of the china foam carrier with respect to silicalite and HZSM-5 are not apparent, and more investigations are required.

\subsection{Microscopic examination of the zeolite coating}

The morphology of the zeolite layer was examined by SEM and is illustrated by the pictures of Fig. 3 . In Fig. 3a, showing a low loaded foam, the surface is partially covered with zeolite nanocrystals that tend to agglomerate in and around the small hollows of the ceramic surface. The agglomeration of the zeolite nanocrystals occurs probably during the drying process. Taking into account the fact that the evaporation of water is slow enough and the viscosity of the zeolite suspension is relatively low, it can be imagined that the suspension film shrink by drying and concentrates around the deeper places on the surface, leaving behind the observed islands of zeolite. The examination of Fig. 3b, a detail from the surface of Fig. 3a, suggests that a certain deformation of the zeolite nanocrystals occurred perpendicularly to the surface, as if they tend to "wet" the ceramic surface. A continuous zeolite layer can be seen only at higher loading as in Fig. 3c, where a section through the silicalite layer is represented. The layer appears to be uniform and well bounded to the surface, as shown by the detail in Fig. 3d.

In order to test the adherence of the silicalite layer at the foam surface, a piece of loaded ceramic monolith ( $3 \mathrm{~g}$ zeolite $/ \mathrm{m}^{2}$ foam) was introduced in a glass reactor and air was allowed to flow at $293 \mathrm{~K}$ and $1 \mathrm{~m} / \mathrm{s}$ linear velocity through the sample. After $48 \mathrm{~h}$ the zeolite loading of the sample was again measured by BET. About a 10\% loss compared to the initial zeolite loading was found. However, some of this quantity could have been lost because of the mechanical shocks during the fixation of the sample in the reactor.

\section{Conclusion}

The present work demonstrates the possibility to coat ceramic monoliths with zeolite nanocrystals without addition of binding materials by simply dipping the ceramic body in an aqueous suspension of zeolite. The amount of zeolite loaded can be controlled by the zeolite content of the suspension. At low amounts of zeolite coated, the crystals tend to agglomerate in and around the irregularities of the carrier surface. This drawback can be probably diminished by enhancing the evaporation rate and the viscosity of the zeolite suspension. Further research will be carried on in this direction, to achieve a uniform coating at low coverage grades. At higher zeolite contents, the washcoat covers uniformly the carrier surface.

\section{Acknowledgements}

The present work was financially supported by the Deutsche Forschungsgemeinschaft. We thank Dr. B. Hochstein for the viscosity measurements.

\section{References}

[1] M.V. Twigg, J.T. Richardson, in: G. Poncelet, J. Martens, B. Delmon, P.A. Jacobs, P. Grange (Eds.), Stud. Surf. Sci. Catal. 91 (1995) 345-359. 
[2] B.A.A.L. van Setten, J. Bremmer, S.J. Jelles, M. Makkee, J.A. Moulijn, Catal. Today 53 (1999) 613-621.

[3] I. Cerri, G. Saracco, V. Specchia, Catal. Today 60 (2000) 21-32.

[4] X. Xu, J.A. Moulijn, in: B. Delmon, P.A. Jacobs, R. Maggi, J.A. Martens, P. Grange, G. Poncelet (Eds.), Stud. Surf. Sci. Catal. 118 (1998) 845-854.

[5] X. Xu, H. Vonk, A. Cybulski, J.A. Moulijn, in: B. Delmon, P.A. Jacobs, R. Maggi, J.A. Martens, P. Grange, G. Poncelet (Eds.), Stud. Surf. Sci. Catal. 91 (1995) 1069-1078.

[6] Z.S. Rak, H.J. Veringa, React. Kinet. Catal. Lett. 60 (1997) 303-312.
[7] H. Suzuki, US 4699892 (1987).

[8] R.K. Grasselli, R.M. Lago, R.F. Socha, J.G. Tsikoyiannis, US 5310714 (1994).

[9] J.E. Antia, R. Govind, Appl. Catal. A 131 (1995) 107-120.

[10] G.B.F. Seijger, O.L. Oudshoorn, W.E.J. van Kooten, J.C. Jansen, H. van Bekkum, C.M. ven den Bleek, H.P.A. Calis, Micropor. Mesopor. Mater. 39 (2000) 195-204.

[11] C.D. Chang, C.T.W. Chu, R.F. Socha, J. Catal. 86 (1984) 289-296.

[12] D. Prinz, L. Riekert, Appl. Catal. 37 (1988) 139-154.

[13] J. Saggio-Woyanski, C.E. Scott, W.P. Minnear, Am. Ceram. Soc. Bull. 71 (1992) 1674-1682. 